\title{
Standard operating procedures improve acute neurologic care in a sub-Saharan African setting OPEN
}

Lamin E.S. Jaiteh, MD* Stefan A. Helwig* Abubacarr Jagne, MD Andreas RagoschkeSchumm, MD Catherine Sarr, MD Silke Walter, MD Martin Lesmeister, Dipl-Phys Matthias Manitz Sebastian Blaß Sarah Weis Verena Schlund Neneh Bah, MD Jil Kauffmann Mathias Fousse, MD Sabina Kangankan, MD Asmell Ramos Cabrera, MD

Kai Kronfeld, $\mathrm{PhD}$

Christian Ruckes,

Dipl-Math

Yang Liu, MD

Ousman Nyan, MD

Klaus Fassbender, MD

Correspondence to Prof. Fassbender: Klaus.Fassbender@uks.eu

\section{Supplemental data} at Neurology.org

\section{ABSTRACT}

Objective: Quality of neurologic emergency management in an under-resourced country may be improved by standard operating procedures (SOPs).

Methods: Neurologic SOPs were implemented in a large urban (Banjul) and a small rural (Brikama) hospital in the Gambia. As quality indicators of neurologic emergency management, performance of key procedures was assessed at baseline and in the first and second implementation years.

Results: At Banjul, 100 patients of the first-year intervention group exhibited higher rates of general procedures of emergency management than 105 control patients, such as neurologic examination (99.0\% vs $91.4 \% ; p<0.05)$ and assessments of respiratory rate $(98.0 \%$ vs $81.9 \%, p<$ $0.001)$, temperature $(60.0 \%$ vs $36.2 \% ; p<0.001)$, and glucose levels $(73.0 \%$ vs $58.1 \% ; p<$ $0.05)$, in addition to written directives by physicians ( $96.0 \%$ vs $88.6 \%, p<0.05)$, whereas assessments of other vital signs remained unchanged. In stroke patients, rates of stroke-related procedures increased: early CT scanning (24.3\% vs 9.9\%; $p<0.05)$, blood count (73.0\% vs 49.3\%; $<<0.01$ ), renal and liver function tests ( $50.0 \%$ vs $5.6 \%, p<0.001$ ), aspirin prophylaxis (47.3\% vs $9.9 \%$; $p<$ 0.001 ), and physiotherapy (41.9\% vs $4.2 \% ; p<0.001$ ). Most effects persisted until the secondyear evaluation. SOP implementation was similarly feasible and beneficial at the Brikama hospital. However, outcomes did not significantly differ in the hospitals.

Conclusions: Implementing SOPs is a realistic, low-cost option for improving process quality of neurologic emergency management in under-resourced settings.

Classification of evidence: This study provides Class IV evidence that, for patients with suspected neurologic emergencies in sub-Saharan Africa, neurologic SOPs increase the rate of performance of guideline-recommended procedures. Neurology ${ }^{\circledR}$ 2017;89:144-152

\section{GLOSSARY}

CBC = complete blood count; GOS = Glasgow Outcome Scale; $\mathbf{m R S}=$ modified Rankin Scale; SOP = standard operating procedure.

Acute neurologic diseases are an important cause of disability and death in sub-Saharan Africa, a region with approximately 800 million people and one of the poorest in the world. ${ }^{1-3}$ They result in large costs for families and societies, further impeding the economic progress of these countries. ${ }^{4,5}$

Common neurologic emergencies in sub-Saharan Africa are cerebrovascular diseases, meningoencephalitis, and epileptic seizures. Cerebrovascular diseases are increasingly frequent and associated with a poor outcome. ${ }^{6-13}$ Moreover, meningoencephalitis is frequent (meningitis belt) ${ }^{5,14,15}$ and associated with high mortality. ${ }^{16}$ Also, epilepsy frequently manifests itself as a neurologic emergency, ${ }^{16}$ with status epilepticus being an important cause of premature death among these patients. ${ }^{17-19}$

\footnotetext{
*These authors contributed equally to this work.

From the Departments of Medicine and Surgery (L.E.S.J., A.J., C.S., N.B., S.K., A.R.C., O.N.), Edward Francis Small Teaching Hospital, Banjul, the Gambia; Department of Neurology (S.A.H., A.R.-S., S.W., M.L., M.M., S.B., S.W., V.S., J.K., M.F., Y.L., K.F.), Saarland University Medical Center, Homburg; and Interdisciplinary Centre for Clinical Trials (IZKS) (K.K., C.R.), Mainz, Germany.

Go to Neurology.org for full disclosures. Funding information and disclosures deemed relevant by the authors, if any, are provided at the end of the article. The Article Processing Charge was funded by the authors.

This is an open access article distributed under the terms of the Creative Commons Attribution-NonCommercial-NoDerivatives License 4.0 (CC BY-NC-ND), which permits downloading and sharing the work provided it is properly cited. The work cannot be changed in any way or used commercially without permission from the journal.
} 
Despite the enormous recent advancement in the field of acute neurology, most patients in developing countries do not profit from this. ${ }^{1,17,20-24}$ There, acute neurologic patients usually do not receive evidence-based treatments that are standard in the Western world. ${ }^{25-33}$ An important reason is the scarcity of neurologists and neurologic services. ${ }^{1,17,20-24}$ Indeed, many countries such as the Gambia have none at all. ${ }^{24}$

Because there is only a small likelihood that sub-Saharan African countries will possess the financial resources necessary for overcoming this

Table 1 Standard operating procedures (SOPs) for general and syndromespecific neurologic emergency management ${ }^{a}$

\section{SOP general neurologic emergency management}

Structured storage and maintenance of medication and equipment

Standardized history

Standardized medical and neurologic examination (including Glasgow Coma Scale and Gambia neurologic emergency screen ${ }^{\text {b) }}$

Standardized and rapid assessment of vital signs (blood pressure, heart and respiratory rates, temperature) and blood glucose levels, as well as ECG

\section{SOP stroke}

If acute ( $<24 \mathrm{~h})$ symptoms of stroke or of stupor or coma still persist or are fluctuating at admission (high priority level): fastest possible CT scan, CBC, and tests of renal (electrolytes, creatinine, urea) and liver (alanine transaminase, aspartate transaminase,

$\gamma$-glutamyltransferase) function

If cause of reduced consciousness still remains unclear after CT: CSF analysis, toxicologic screening

Early secondary prevention with aspirin $100 \mathrm{mg}$ after exclusion of hemorrhage by CT

Blood pressure adjustment according to $\mathrm{SOP}^{\mathrm{c}}$

Physiotherapy

SOP fever and headache

$\mathrm{CBC}$

If meningeal signs persist at admission (high priority level): CSF analysis, renal and liver laboratory function test

Optional CT scan

Antibiotic treatment according to SOP

\section{SOP seizures}

If seizures or status epilepticus persist at admission (high priority level): CT scan, laboratory tests (CBC, tests for renal and liver function)

If origin of seizures remains unclear: CSF analysis, toxicologic screening

Anticonvulsive treatment according to SOP

Abbreviation: $\mathrm{CBC}=$ complete blood count.

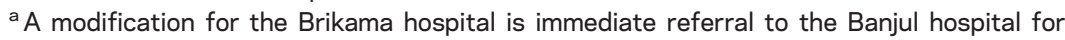
high-priority stroke patients for CT scan, or if requested work-up is not possible.

${ }^{b}$ Gambia neurologic emergency screen: acute occurrence of $\geq 1$ of the following: (1) paresis in face, arms, or legs; (2) abnormal speech; (3) disorders of pupils, vision, or oculomotor function; (4) Babinski or meningeal signs; and (5) impaired defense reflexes.

${ }^{\mathrm{c}}$ Target blood pressure in ischemic stroke: $<200 \mathrm{~mm} \mathrm{Hg}$ systolic in the first 72 hours; target blood pressure in hemorrhagic stroke: $<140 \mathrm{~mm} \mathrm{Hg}$ systolic.

${ }^{d}$ If nonepidemic, ceftriaxone $2 \mathrm{~g} / \mathrm{d}$ for 5 days administered intramuscularly (IM) or IV, or chloramphenicol $100 \mathrm{mg} / \mathrm{kg} \mathrm{IM}$; second dose if no improvement after 24 hours; if epidemic, ceftriaxone $100 \mathrm{mg} / \mathrm{kg}$, single dose IM or IV; second dose if no improvement after 24 hours; treat up to 5 days.

${ }^{\text {e}}$ Diazepam $10 \mathrm{mg}$; if seizures persist, valproic acid, phenytoin, or diazepam $5 \mathrm{mg}$ repetitively. treatment gap, an immediately realizable and low-cost option may be to make better use of the limited available resources. Standard operating procedures (SOPs) may prevent undesirable variations in the treatment of otherwise similar cases and assist in streamlining processes. Here, we studied the effects of SOPs on the quality of neurologic emergency management in a resource-poor sub-Saharan setting.

METHODS Setting and patients. This interventional study was performed in the Gambia, a small sub-Saharan African country with approximately 1,900,000 inhabitants. The study was performed simultaneously in a large urban teaching hospital (The Edward Francis Small Teaching Hospital, Banjul, with 500 beds, treating approximately 25,000 patients annually) and in a small rural hospital (Brikama Major Health Centre, with 54 beds, treating approximately 12,000 patients annually).

Inclusion criteria were (1) suspected neurologic emergencies, defined as conditions manifesting themselves as acute symptoms severe enough to require immediate medical attention, (2) age $\geq 14$ years, and (3) provision of informed written consent by patients or closest proxies. Exclusion criteria were nonacute conditions and traumatic brain injuries.

Study design. In a stepwise approach, we first obtained by use of a questionnaire a baseline of quality indicators of neurologic emergency management in consecutive patients over a study period of 8 weeks (February 11-April 1, 2014) in Banjul and Brikama. We implemented SOPs for neurologic emergency management on October 1, 2014 (table 1).

The intervention was implemented via the following training activities. (1) One intensive training session for the Gambian teachers (L.E.S.J., A.J., C.S.) in Germany for approximately 4 weeks. (2) Four larger onsite group sessions for training all physicians and nurses in the use of the SOPs. The first took place before the introduction of the SOPs, and the refresher training sessions took place approximately every 6 months. (3) At these meetings, apart from oral presentations, laminated pocket cards of the SOPs (one for each syndrome entity) and further written explanations were distributed to all involved physicians and medical students in the Department of Medicine by L.E.S.J., A.J., S.A.H., and C.S. (4) Moreover, during morning conferences attended by all relevant physicians, information about the use of the neurologic SOPs was repeated, and interesting cases were presented approximately monthly.

The assessment using the same questionnaires was, in the same season, repeated in 2015 (March 9-April 29) in both hospitals and in 2016 (February 24-April 20) in Banjul alone. Enrollment and assessment of patient management were performed by dedicated study investigators (visiting and local physicians not engaged in routine services, e.g., on maternity leave), whose role was strictly observational. Study visits occurred at admission, on day 5 ( \pm 1 day), and at discharge. This study with a before-after design aimed to provide Class IV evidence for the effects of implementation of neurologic SOPs on quality indicators of neurologic emergency management.

SOPs for neurologic emergency management. In a series of meetings in the Gambia and in Germany, followed by e-mail discussions, participants in both cooperating groups (L.E.S.J., S.A.H., A.J., A.R.-S., S.W., S.B., V.S., O.N., and K.F.) reviewed the current international ${ }^{25,27,28,30-32}$ and South African 
guidelines ${ }^{26,29,33}$ regarding the following neurologic emergency entities: stroke, meningitis/encephalitis, and seizures. Measures (1) that did not address acute management and (2) for which there was consensus that they were not feasible or were without therapeutic consequences in this specific sub-Saharan study setting were not considered for this SOP intervention.

The SOPs addressed both general procedures for neurologic emergency management and syndrome-specific procedures. The SOP general neurologic emergency management (table 1) addressed the fastest possible neurologic examination and assessment of vital signs, blood glucose level, and ECG, apart from structured storage and maintenance of neurologic equipment. For the identification of neurologic emergencies in a setting without neurologists, we developed a tool that screens for acute neurologic symptoms (Gambia neurologic emergency screen; table 1).

The SOP stroke (table 1) was to be used for patients with acute focal neurologic symptoms or stupor and coma. If symptoms that had occurred within the previous 24 hours and still persisted or fluctuated at admission, or if stupor or coma was present (defining a high priority level), the SOP recommended the fastest possible CT scan, complete blood count $(\mathrm{CBC})$, and laboratory tests for renal and liver function to be carried out (table 1). If the cause of reduced consciousness remained unclear after CT evaluation, the SOP recommended CSF analysis and toxicologic screening tests. Therapeutically, after CT scan, the SOP mandated early secondary prevention with aspirin $(100 \mathrm{mg})$, blood pressure management, and physiotherapy.

The SOP fever and headache (table 1) recommended CBC and, optionally, a CT scan. If meningeal signs were present at admission (high priority level), tests of CSF and of renal and liver function were recommended. An antibiotic treatment regimen was specified.

For patients with seizures, the SOP seizures (table 1) was used. If seizures were present at admission (high priority level), the SOP mandated a CT scan and laboratory tests $(\mathrm{CBC}$, renal and liver function) and if the cause still remained unclear, CSF analysis and toxicologic tests were recommended. An anticonvulsive treatment was specified.

Indicators of quality of neurologic emergency management. As indicators of quality of general neurologic emergency management, we assessed performance of guideline-recommended procedures: neurologic examinations, assessment of vital signs, and performance of blood glucose tests and ECG (table 1), in addition to written directives by a physician.

As indicators of quality of stroke-specific neurologic emergency management, we used, in addition, performance of early CT scan, hepatic and renal laboratory tests, early secondary aspirin prophylaxis (after CT), blood pressure management, and physiotherapy. As quality indicators of management of patients with the syndromes fever and headache and seizures, we analyzed the performance of recommended blood and CSF tests, imaging, toxicologic screening, and the administration of antibiotics or anticonvulsants.

Finally, we assessed mortality, Glasgow Outcome Scale (GOS) scores, modified Rankin Scale (mRS) scores, and NIH Stroke Scale scores (for stroke patients) at discharge.

Monitoring of the study. The trial was monitored by an independent clinical monitor (Interdisciplinary Centre for Clinical Trials, Mainz, Germany). Source data were compared with both questionnaires and databases. For remote monitoring in Germany, the original patient files were photographed at the study site and then destroyed after the subsequent monitoring process in Germany.

Standard protocol registrations, approvals, and patient consents. The study and the subject information documents were approved by the Medical Research Council Ethics Committee of the Gambia (R 130013). All patients provided written informed consent (in their native language) to participate in the study. For patients aged 14-18 years, or those with a communication disability, written informed consent was obtained from the closest proxies.

Figure 1 Consolidated Standards of Reporting Trials flow diagram of the study population at the Banjul hospital

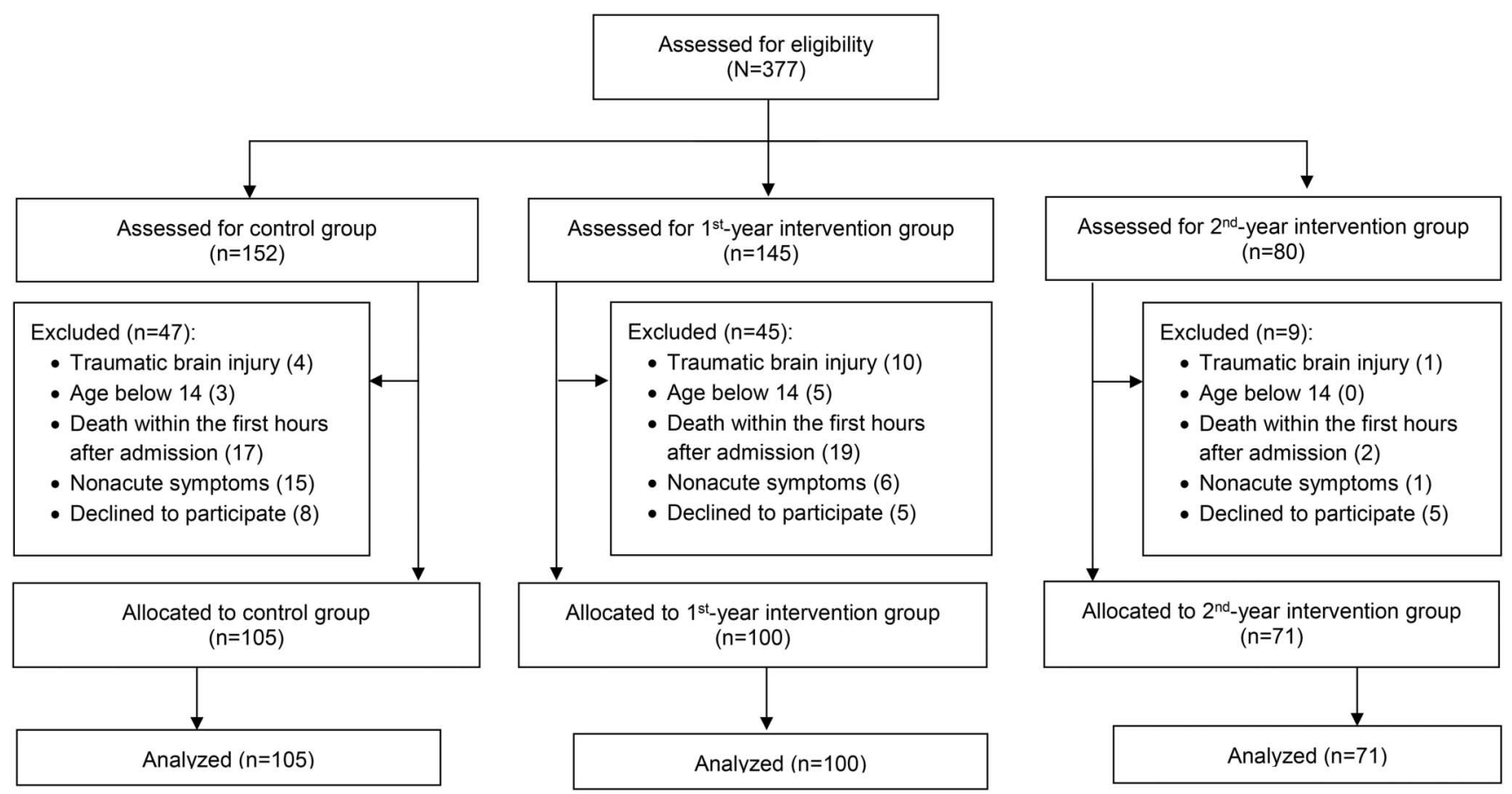


Statistical analysis. Differences between the study groups were detected with the Mann-Whitney $U$ test. The $\chi^{2}$ test and Fisher exact test were used to analyze categorical variables. IBM SPSS Statistics for Windows, version 23.0.0.2 (IBM, Armonk, NY), software was used.

RESULTS Study population at the Banjul hospital. In the urban hospital at Banjul, 152 patients during the baseline assessment in 2014 were screened for possible study participation, and 105 were enrolled in the study as the baseline group. In 2015, 145 patients were screened for inclusion, and 100 were enrolled. During the study period in 2016,80 patients were screened for inclusion, and 71 were included (figure 1).

Demographic variables, risk factor profiles, referral status, disease severity, and pattern of suspected initial and final diagnoses (table 2) and sociodemographic details (table e-1 at Neurology.org) of the study populations in the Banjul hospital were within the same range. In all study groups, stroke was the most common suspected and final diagnosis. In contrast, although meningoencephalitis and seizures were more frequently suspected at admission, they were unexpectedly rare final diagnoses (table 2), impairing further statistical evaluation of these diagnostic subgroups.

Effects on quality of general neurologic emergency management at the Banjul hospital. Performance of key procedures of general neurologic emergency management in the first intervention year (neurologic examination, assessments of respiratory rates, temperature, and glucose level, and written directives by a physician) and in the second intervention year (assessment of respiratory rate and glucose level and written directives by a physician) were higher than at baseline (table 3). In contrast, the rates of assessing blood pressure and heart rate, which had already been $>95 \%$ at baseline, did not improve further. The rate of performance of ECG, however, was lower in 2015 and 2016 than in 2014 because of problems with the supply of ECG paper (table 3).

Effects on quality of stroke-related emergency management at the Banjul hospital. The rates of performance of stroke-specific neurologic procedures were higher in both intervention groups than in the baseline group (table 4). In contrast to the total number of CTs, the number of CTs performed within 8 hours (urgent CT) was significantly higher in the first-year intervention group than in the baseline group, a finding that was also related to these patients' placement in the high-priority group (table 4). However, in the second-year intervention group, the rate of urgent CTs did not differ. Laboratory examinations (CBC and renal and liver function tests) were performed significantly more often during the first and second years of intervention. The proportion of early secondary prevention with aspirin (after CT scanning) was approximately 5 times higher in the first- year and in the second-year intervention groups than in the baseline group (table 4). Rate of administration of antihypertensives tended to be higher in the first year and was significantly higher in the second year. Importantly, the proportion of patients for whom physiotherapy was performed was approximately 10 times higher in both the first-year and second-year intervention groups than in the baseline group (table 4).

Effects on clinical outcomes at the Banjul hospital. Clinical outcomes (as determined by GOS scores, mRS scores, and mortality rates) at discharge showed a trend toward improvement that was not statistically significant (tables 3 and 4).

Effects of SOPs at the Brikama hospital. The SOP intervention was performed in parallel at the rural hospital in Brikama, where 49 patients were screened for possible study participation, and 28 were enrolled in the study as a baseline group. During the study period in 2015, 36 patients were screened for inclusion, and 25 were enrolled as an intervention group (figure e-1). Demographic and medical profiles (table 2) and additional socioepidemiologic details (table e-1) were within the same range. No patient in Brikama was treated according to more than one SOP.

In this rural hospital, the rates of performance of most (heart rate, respiratory rate, temperature, blood glucose level) but not all (blood pressure, ECG, and written directive by a physician) procedures of general neurologic emergency management were significantly higher in the intervention group than in the baseline group (table e-2). Among patients with suspected stroke and of a high priority level, 4 from the intervention group had CT scan (after transfer to the Banjul hospital) in contrast to none in the baseline group (table e-3). In Brikama, although the rate of general aspirin prevention was unchanged, the rate of CTconfirmed aspirin prevention relatively increased. The rates of blood pressure measurement and medication and of physiotherapy were not significantly different (table e-3). At Brikama, no significant differences were observed in mortality rates or clinical outcomes between the 2 groups (tables e- 2 and e- 3 ).

DISCUSSION Enormous advances have been made in the treatment of acute neurologic diseases; however, in developing countries, most neurologic patients cannot benefit from this progress. This study conducted in 2 exemplary urban and rural hospitals shows that, in an under-resourced sub-Saharan country without neurologists, the implementation of SOPs significantly improves the quality of general and syndrome-specific neurologic emergency management.

In this study, acute stroke composed the majority of neurologic emergencies, whereas the proportion of acute brain infections or seizures was unexpectedly 
Table 2 Demographic and medical variables of the study groups at the Banjul hospital and the Brikama hospital

\begin{tabular}{|c|c|c|c|c|c|}
\hline Variables $^{a}$ & \multicolumn{3}{|l|}{ Banjul } & \multicolumn{2}{|l|}{ Brikama } \\
\hline Age, y & 49 (31-62) & $52(37-65)$ & $58(45-69)$ & $54(43-66)$ & $55(41-68)$ \\
\hline $\mathrm{F} ; \mathrm{M}$ & $40 ; 65$ & $58 ; 42$ & $35 ; 36$ & $13 ; 15$ & $17 ; 8$ \\
\hline Hypertension & $55(52.4)$ & $53(53.0)$ & $49(69.0)$ & $15(53.6)$ & $16(64.0)$ \\
\hline Diabetes & 19 (18.1) & 19 (19.0) & $11(15.5)$ & $4(14.3)$ & $5(20.0)$ \\
\hline Smoking & $18(17.1)$ & $16(16.0)$ & $10(14.1)$ & $4(14.3)$ & $3(12.0)$ \\
\hline Alcohol & $5(4.8)$ & $0(0)$ & $0(0)$ & $1(3.6)$ & $0(0)$ \\
\hline From other hospitals & $29(27.6)$ & $28(28.0)$ & $33(46.5)$ & $0(0)$ & $0(0)$ \\
\hline From Brikama Major Health Centre & 14 (13.3) & 15 (15.0) & $9(12.7)$ & & \\
\hline From primary health stations & 35 (33.3) & 37 (37.0) & $18(25.4)$ & $7(25.0)$ & $4(16.0)$ \\
\hline Symptom onset to admission, $\min$ & $865(342-1,771)$ & $1,464(252-4,593)$ & $466(236-2,214)$ & $240(90-1,050)$ & $199(68-835)$ \\
\hline \multicolumn{6}{|l|}{ Disease severity at admission } \\
\hline GCS score & $13(7-15)$ & $13(9-15)$ & $11(7-15)$ & $15(8-15)$ & $13(9-15)$ \\
\hline mRS score & $4(3-5)$ & $5(4-5)$ & $4(4-5)$ & $4(1-4)$ & $4(4-5)$ \\
\hline mRS score (in stroke patients) & $5(4-5)$ & $5(4-5)$ & $4(4-5)$ & $4(2-5)$ & $4(4-4)$ \\
\hline NIHSS score (in stroke patients) & $12(6-23)$ & $11(4-17)$ & $12(7-21)$ & $14(3-22)$ & $9(4-13)$ \\
\hline Hemorrhagic & $6(5.7)$ & $12(12.0)$ & $12(16.9)$ & $0(0)$ & $0(0)$ \\
\hline No CT & 24 (22.9) & $15(15.0)$ & $11(15.5)$ & 9 (32.1) & 8 (32.0) \\
\hline Meningoencephalitis, suspected diagnosis ${ }^{b}$ & 20 (19.0) & $15(15.0)$ & $10(14.1)$ & $7(25.0)$ & $5(20.0)$ \\
\hline Meningoencephalitis, final diagnosis & $13(12.4)$ & $6(6.0)$ & $4(5.6)$ & $4(14.3)$ & $1(4.0)$ \\
\hline Seizure, suspected diagnosis ${ }^{b}$ & 14 (13.3) & $20(20.0)$ & $20(28.2)$ & $6(21.4)$ & $4(16.0)$ \\
\hline Seizure, final diagnosis & $12(11.4)$ & $16(16.0)$ & $19(26.8)$ & 4 (14.3) & $4(16.0)$ \\
\hline Other or unclear & 34 (32.4) & 19 (19.0) & 15 (21.1) & 12 (42.9) & $6(24.0)$ \\
\hline
\end{tabular}

Abbreviations: GCS = Glasgow Coma Scale; $\mathrm{mRS}=$ modified Rankin Scale; NIHSS = NIH Stroke Scale.

a Unless otherwise indicated, data are presented as median (interquartile range).

${ }^{\mathrm{b}}$ In the control group in Banjul, 1 patient with suspected stroke had additional suspected seizure. In the first year intervention group, 7 patients with suspected stroke had additional suspected seizures, 1 patient with suspected stroke had additional suspected meningoencephalitis, and 1 patient with suspected meningoencephalitis had additional suspected seizure. In the second year intervention group, 12 patients with suspected stroke had additional suspected seizures, 1 patient with suspected stroke had additional suspected meningoencephalitis, and 2 patients with suspected meningoencephalitis had additional suspected seizure. In Brikama, no patient was assigned to more than one syndrome category.

low. The very high prevalence of cerebrovascular diseases in developing countries has previously been placed in context with shift toward increased prevalence of vascular risk factors. ${ }^{2,11-13,34}$

When stroke was suspected, guidelinerecommended performance of urgent ( $\leq 8$ hours)
CT increased in relation to the priority level, although this effect was evident only in the first but not the second intervention year.

Laboratory tests $(\mathrm{CBC}$, renal and hepatic function test) were performed significantly more frequently in both intervention years than at baseline. 


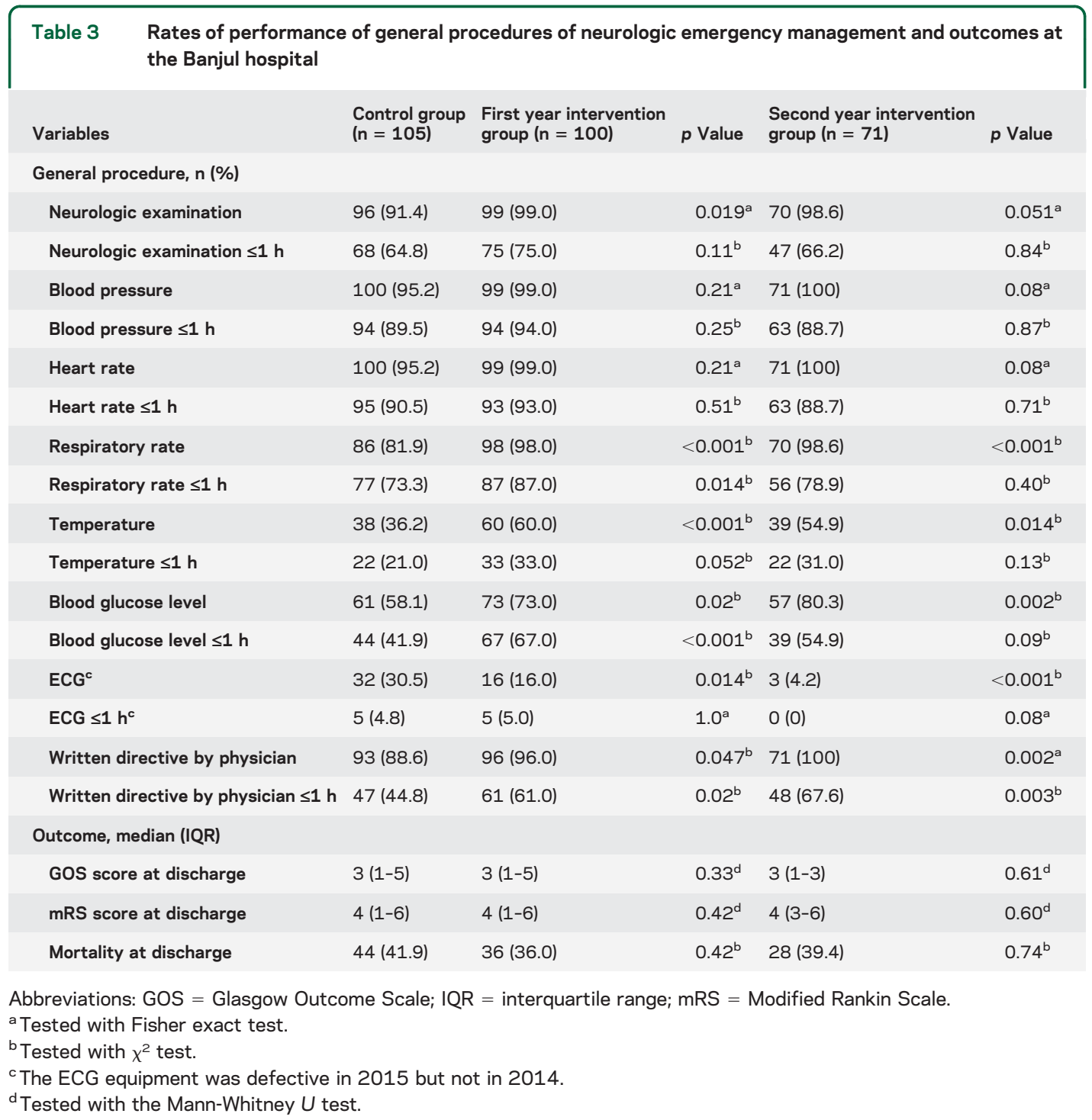

Despite being recommended in stroke guidelines, ${ }^{25-27}$ aspirin, an inexpensive and effective prophylactic treatment, is usually not administered after exclusion of hemorrhage by CT or not administered at all in developing countries. ${ }^{35}$ Although secondary prevention with aspirin without exclusion of hemorrhage has recently been calculated to be costeffective, ${ }^{36}$ imaging clearly increases the safety of this antithrombotic treatment. In our study, implementation of the SOPs was associated with an approximately 5 -fold increase in the frequency of aspirin prophylaxis with prior exclusion of hemorrhage by CT. The use of aspirin $\leq 48$ hours, although still significantly increased, decreased from year 1 to year 2 , a finding that may be related to the fact that the rate of urgent CTs needed for previous exclusion of hemorrhage also decreased.

Finally, physiotherapy is recommended for reducing disability and preventing complications such as pneumonia or deep venous thrombosis. ${ }^{25-27}$ Importantly, approximately 10 times more stroke patients in the intervention group than in the baseline group received physiotherapy, an effect that persisted in the second-year evaluation.

The SOP intervention was performed in parallel at Brikama, a small rural hospital. There, we observed similar beneficial effects of the SOPs on rates of procedures of neurologic emergency management, a finding suggesting generalizability of the strategy of neurologic SOPs for under-resourced settings. It might be of interest to study whether, more generally, such SOPs may also be useful in other areas of medical care, e.g., in management of other major medical problems of this region such as HIV/AIDS and malaria, although, as chronic diseases, they were beyond the focus of this study on neurologic emergency management.

In all study groups, mortality rates associated with neurologic emergencies were approximately $40 \%$, consistent with rates found by earlier studies. ${ }^{8-10,15,17-19}$ Although a trend toward better clinical outcomes was observed, these differences did not reach statistical 
Table 4 Rates of performance of stroke-specific procedures and outcomes at the Banjul hospital

\begin{tabular}{|c|c|c|c|c|c|}
\hline Variables $^{a}$ & $\begin{array}{l}\text { Control group } \\
(n=71)\end{array}$ & $\begin{array}{l}\text { First year } \\
\text { intervention } \\
\text { group }(n=74)\end{array}$ & p Value & $\begin{array}{l}\text { Second year } \\
\text { intervention } \\
\text { group }(n=56)\end{array}$ & p Value \\
\hline \multicolumn{6}{|l|}{ CT } \\
\hline Total & 40 (56.3) & 52 (70.3) & 0.08 & 38 (67.9) & 0.19 \\
\hline High priority ${ }^{b}$ & 22/38 (57.9) & $30 / 46$ (65.2) & 0.49 & 28/39 (71.8) & 0.20 \\
\hline Low priority ${ }^{b}$ & 18/33 (54.5) & 22/28 (78.6) & 0.049 & $10 / 17(58.8)$ & 0.77 \\
\hline Immediate ( $\leq 1 \mathrm{~h})$ & $2(2.8)$ & $4(5.4)$ & $0.68^{c}$ & 2 (3.6) & $1.0^{c}$ \\
\hline High priority & 0/38 (0) & $3 / 46(6.5)$ & $0.25^{\mathrm{c}}$ & $1 / 39(2.6)$ & $1.0^{c}$ \\
\hline Low priority ${ }^{b}$ & 2/33 (6.1) & 1/28 (3.6) & $1.0^{c}$ & $1 / 17(5.9)$ & $1.0^{c}$ \\
\hline Urgent ( $\leq 8 \mathrm{~h})$ & 7 (9.9) & $18(24.3)$ & 0.021 & 5 (8.9) & $0.86^{c}$ \\
\hline High priority ${ }^{b}$ & $3 / 38$ (7.9) & 11/46 (23.9) & 0.0499 & 2/39 (5.1) & $0.67^{c}$ \\
\hline Low priority ${ }^{b}$ & $4 / 33(12.1)$ & $7 / 28(25.0)$ & 0.19 & $3 / 17$ (17.6) & $0.68^{c}$ \\
\hline \multicolumn{6}{|l|}{ Laboratory } \\
\hline Complete blood count & 35 (49.3) & 54 (73.0) & 0.003 & 39 (69.6) & 0.02 \\
\hline High priority ${ }^{b}$ & 22/38 (57.9) & $34 / 46$ (73.9) & 0.12 & $25 / 39(64.1)$ & 0.58 \\
\hline Low priority ${ }^{b}$ & 13/33 (39.4) & 20/28 (71.4) & 0.012 & 14/17 (82.4) & 0.004 \\
\hline Renal and liver function tests & $4(5.6)$ & $37(50.0)$ & $<0.001$ & $31(55.4)$ & $<0.001$ \\
\hline High priority ${ }^{b}$ & 2/38 (5.3) & $23 / 46(50.0)$ & $<0.001$ & 20/39 (51.3) & $<0.001$ \\
\hline Low priority ${ }^{b}$ & $2 / 33(6.1)$ & $14 / 28(50.0)$ & $<0.001$ & $11 / 17(64.7)$ & $<0.001^{\mathrm{c}}$ \\
\hline Blood drawn $\leq 1 \mathrm{~h}$ & $12(16.9)$ & $19(25.7)$ & 0.20 & $28(50.0)$ & $<0.001$ \\
\hline High priority ${ }^{b}$ & 8/38 (21.1) & 9/46 (19.6) & 0.87 & $19 / 39$ (48.7) & 0.011 \\
\hline Low priority ${ }^{b}$ & $4 / 33(12.1)$ & $10 / 28(35.7)$ & 0.029 & 9/17 (52.9) & $0.005^{c}$ \\
\hline \multicolumn{6}{|l|}{ Therapy } \\
\hline Aspirin prevention & 7 (9.9) & $35(47.3)$ & $<0.001$ & $21(37.5)$ & $<0.001$ \\
\hline CT confirmed ischemic strokes & $3 / 17(17.6)$ & $30 / 36(83.3)$ & $<0.001$ & 18/22 (81.8) & $<0.001$ \\
\hline CT confirmed hemorrhagic strokes & $0 / 6(0)$ & $0 / 10(0)$ & - & $0 / 12(0)$ & - \\
\hline Other or unclear & $4 / 48(8.3)$ & $5 / 28(17.9)$ & $0.28^{c}$ & $3 / 22(13.6)$ & $0.67^{c}$ \\
\hline Aspirin prevention $\leq 48 \mathrm{~h}$ & $3(4.2)$ & $23(31.1)$ & $<0.001$ & $10(17.9)$ & 0.012 \\
\hline \multicolumn{6}{|l|}{ Blood pressure control } \\
\hline Blood pressure measurement & $67(94.4)$ & 74 (100) & $0.055^{c}$ & $56(100)$ & $0.13^{c}$ \\
\hline Blood pressure measurement $\leq 1 \mathrm{~h}$ & $63(88.7)$ & 70 (94.6) & 0.20 & 50 (89.3) & 0.92 \\
\hline Use of antihypertensives & 25 (35.2) & 31 (41.9) & 0.49 & $36(64.3)$ & 0.002 \\
\hline Use of antihypertensives $\leq 1 \mathrm{~h}$ & $11(15.5)$ & $7(9.5)$ & 0.27 & $12(21.4)$ & 0.39 \\
\hline Physiotherapy ${ }^{d}$ & $3(4.2)$ & 31 (41.9) & $<0.001$ & 22 (39.3) & $<0.001$ \\
\hline \multicolumn{6}{|l|}{ Outcome, median (IQR) } \\
\hline GOS score at discharge & $1(1-3)$ & $3(1-4)$ & $0.08^{\mathrm{e}}$ & $3(1-3)$ & $0.71^{\mathrm{e}}$ \\
\hline mRS score at discharge & $6(3-6)$ & $4(3-6)$ & $0.13^{e}$ & $4(4-6)$ & $0.74^{e}$ \\
\hline NIHSS score at discharge & $6(2-12)$ & $2(0-10)$ & $0.17^{e}$ & $3(1-8)$ & $0.14^{\mathrm{e}}$ \\
\hline Mortality at discharge & 35 (49.3) & 27 (36.5) & 0.12 & $26(46.4)$ & 0.75 \\
\hline
\end{tabular}

Abbreviations: GOS = Glasgow Outcome Scale; IQR = interquartile range; $m R S=$ Modified Rankin Scale; NIHSS $=\mathrm{NIH}$ Stroke Scale.

${ }^{a}$ Unless otherwise indicated, values are presented as $\mathrm{n}(\%)$ and tested with the $\chi^{2}$ test.

${ }^{b}$ For triage with regard to limited resources, high and low priority levels were specified by the standard operating procedure.

${ }^{\mathrm{c}}$ Fisher exact test was used to analyze these variables.

${ }^{\mathrm{d}}$ Time of onset of physiotherapy was not documented.

${ }^{\mathrm{e}}$ Tested with the Mann-Whitney $U$ test. 
significance. Recently, in the neurology unit of a Ugandan hospital, a stroke pathway for patients with CT-diagnosed stroke was implemented; this pathway, combined with the provision of missing resources, slightly improved certain outcomes only in a subpopulation of patients with severe strokes. ${ }^{37}$

One limitation of this study is the lack of randomization to treatment protocols that did not appear to be feasible in this sub-Saharan African setting for ethical reasons. Moreover, people may tend to function better when they are being observed. However, the conditions of the assessments before and after the SOP implementation were identical, thereby limiting this potential bias. A further limitation is that the neurologic screening tool was not validated in an additional study. In contrast to analysis of time intervals and rates of procedures in which significant differences were found, the power for the analysis of the multifactorial endpoint, outcome, was likely too low. Rather than specific power calculations, only rough estimations have been performed in advance. Differences in outcomes might have been seen with a longer follow-up period, although long-term follow-up is difficult in such settings.

Also, the relevance of certain laboratory tests, such as of renal function, is uncertain in this setting. Reasons for including them were mostly to exclude regionally relevant non-neurologic conditions that may have contributed to the patients' clinical presentation due to the high frequency of renal failure as consequence of uncontrolled hypertension, diabetes, chronic glomerulonephritis, and herbal intoxication and frequent hepatitis associated with an estimated prevalence of hepatitis B viral infection up to $30 \%$.

The existing financial constrains became overt as both timely provision of expensive resources, such as urgent CT, for which financial questions often had to be settled, and the continuous supply of more specialized consumables, such as ECG paper, was hindered. Thus, neurologic SOPs are only one of several necessary steps, among which include long-term international financial support and cooperation; structural measures, such as health insurance systems and systematic training of neurologists (thereby avoiding brain drain); and, finally, implementing neurologic services. ${ }^{23,24}$ All of these steps have previously been defined as goals by the World Federation of Neurology. ${ }^{21}$

The results of this study show that neurologic SOPs in a sub-Saharan African country have longterm beneficial effects on the quality of neurologic emergency management, even in the absence of provision of additional resources. This finding offers a realistic and low-cost option for reducing the detrimental treatment gap for acute neurologic patients in highly under-resourced settings.

\section{AUTHOR CONTRIBUTIONS}

Lamin E.S. Jaiteh: study organization and execution and manuscript review and critique. Stefan A. Helwig: study organization and execution and manuscript review and critique. Abubacarr Jagne: study organization and execution and manuscript review and critique. Andreas Ragoschke-Schumm: study organization and execution and manuscript review and critique. Catherine Sarr: study execution and manuscript review and critique. Silke Walter: study organization and execution and manuscript review and critique. Martin Lesmeister: statistical analysis and manuscript review and critique. Matthias Manitz: study execution and manuscript review and critique. Sebastian Blaß: study organization, execution, manuscript review and critique. Sarah Weis: study execution, manuscript review and critique. Verena Schlund: study execution, manuscript review and critique. Neneh Bah: organization and execution. Jil Kauffmann: study execution, manuscript review and critique. Matthias Fousse: study organization, manuscript review and critique. Sabina Kangankan: study organization and execution. Asmell Ramos Cabrera: organization and execution. Kai Kronfeld: study conception, statistical design, manuscript review and critique. Christian Ruckes: study conception, statistical design, manuscript review and critique. Yang Liu: study organization, manuscript review and critique. Ousman Nyan: study conception, manuscript review and critique. Klaus Fassbender: study conception, organization, execution, manuscript writing, review, and critique.

\section{STUDY FUNDING}

Supported by the Else Kröner-Fresenius-Stiftung. The Article Processing Charge was funded by the University of the Saarland, Germany.

\section{DISCLOSURE}

The authors report no disclosures relevant to the manuscript. Go to Neurology.org for full disclosures.

Received October 6, 2016. Accepted in final form April 11, 2017.

\section{REFERENCES}

1. World Health Organization. Regional Office for Africa. The Health of the People: The African Regional Health Report. Geneva: World Health Organization; 2006. Available at: who.int/bulletin/africanhealth/en/. Accessed July 12, 2016.

2. Philip-Ephraim EE, Eyong KI, Oparah SK, et al. Profile of neurologic emergencies at the accident and emergency department of a tertiary hospital in South Nigeria. J Neurol Sci Turk 2013;30:72-80.

3. GBD 2015 Mortality and Causes of Death Collaborators. Global, regional, and national life expectancy, allcause mortality, and cause-specific mortality for 249 causes of death, 1980-2015: a systematic analysis for the Global Burden of Disease Study 2015. Lancet 2016;388:1459-1544.

4. Etyang AO, Munge K, Bunyasi EW, et al. Burden of disease in adults admitted to hospital in a rural region of coastal Kenya: an analysis of data from linked clinical and demographic surveillance systems. Lancet Glob Health 2014;2:e216-e224.

5. Silberberg D, Katabira E. Neurological disorders. In: Jamison DT, Feachem RG, Makgoba MW, et al, eds. Disease and Mortality in Sub-Saharan Africa. 2nd ed. Washington, DC: World Bank; 2006.

6. Bower JH, Asmera J, Zebenigus M, Sandroni P, Bower SM, Zenebe G. The burden of inpatient neurologic disease in two Ethiopian hospitals. Neurology 2007;68: 338-342.

7. Walker R, Whiting D, Unwin N, et al. Stroke incidence in rural and urban Tanzania: a prospective, community-based study. Lancet Neurol 2010;9:786-792. 
8. Walker RW, McLarty DG, Kitange HM, et al. Stroke mortality in urban and rural Tanzania: adult morbidity and mortality project. Lancet 2000;355:1684-1687.

9. Garbusinski JM, van der Sande MA, Bartholome EJ, et al. Stroke presentation and outcome in developing countries: a prospective study in the Gambia. Stroke 2005;36:1388-1393.

10. Walker RW, Rolfe M, Kelly PJ, George MO, James OF. Mortality and recovery after stroke in the Gambia. Stroke 2003;34:1604-1609.

11. Connor MD, Walker R, Modi G, Warlow CP. Burden of stroke in black populations in sub-Saharan Africa. Lancet Neurol 2007;6:269-278.

12. Feigin VL, Forouzanfar MH, Krishnamurthi R, et al; Global Burden of Diseases, Injuries, and Risk Factors Study 2010 (GBD 2010) and the GBD Stroke Experts Group. Global and regional burden of stroke during 1990-2010: findings from the Global Burden of Disease study 2010. Lancet 2014;383:245-254.

13. O’Donnell MJ, Xavier D, Liu L, et al; INTERSTROKE Investigators. Risk factors for ischaemic and intracerebral haemorrhagic stroke in 22 countries (the INTERSTROKE study): a case-control study. Lancet 2010;376: 112-123.

14. Edmond K, Clark A, Korczak VS, Sanderson C, Griffiths UK, Rudan I. Global and regional risk of disabling sequelae from bacterial meningitis: a systematic review and meta-analysis. Lancet Infect Dis 2010;10:317-328

15. Koutangni $T$, Boubacar Maïnassara H, Mueller JE. Incidence, carriage and case-carrier ratios for meningococcal meningitis in the African meningitis belt: a systematic review and meta-analysis. PLoS One 2015;10:e0116725.

16. Edwards T, Scott AG, Munyoki G, et al. Active convulsive epilepsy in a rural district of Kenya: a study of prevalence and possible risk factors. Lancet Neurol 2008;7:50-56.

17. Ba-Diop A, Marin B, Druet-Cabanac M, Ngoungou EB, Newton CR, Preux PM. Epidemiology, causes, and treatment of epilepsy in sub-Saharan Africa. Lancet Neurol 2014;13:1029-1044.

18. Kariuki SM, Kakooza-Mwesige A, Wagner RG, et al; SEEDS Writing Group. Prevalence and factors associated with convulsive status epilepticus in Africans with epilepsy. Neurology 2015;84:1838-1845.

19. Ngugi AK, Bottomley C, Kleinschmidt I, et al; SEEDS Group. Prevalence of active convulsive epilepsy in subSaharan Africa and associated risk factors: cross-sectional and case-control studies. Lancet Neurol 2013;12:253-263.

20. Dua T; World Federation of Neurology. Programme for Neurological Diseases and Neuroscience, World Health Organization Department of Mental Health and Substance Abuse. Atlas: Country Resources for Neurological Disorders 2004: Results of a Collaborative Study of the World Health Organization and the World Federation of Neurology. Geneva: Programme for Neurological Diseases and Neuroscience, Department of Mental Health and Substance Abuse World Health Organization; 2004. Available at: who.int/mental_health/neurology/epidemiology/en/. Accessed July 11, 2016.

21. Aarli JA, Diop AG, Lochmüller H. Neurology in subSaharan Africa: a challenge for World Federation of Neurology. Neurology 2007;69:1715-1718.

22. Bower JH, Zenebe G. Neurologic services in the nations of Africa. Neurology 2005;64:412-415.

23. Craven R. Building neurological services in Africa. Lancet Neurol 2009;8:32-33.
24. Ogungbo B, Finkel MF, Ogun Y. Building foundations for improving health opportunities in sub-Saharan Africa. Neurology 2013;81:2134-2135.

25. Adams HP Jr, del Zoppo G, Alberts MJ, et al. Guidelines for the early management of adults with ischemic stroke: a guideline from the American Heart Association/American Stroke Association Stroke Council, Clinical Cardiology Council, Cardiovascular Radiology and Intervention Council, and the Atherosclerotic Peripheral Vascular Disease and Quality of Care Outcomes in Research Interdisciplinary Working Groups: the American Academy of Neurology affirms the value of this guideline as an educational tool for neurologists. Circulation 2007;115:e478-e534.

26. Bryer A, Connor M, Haug P, et al. South African guideline for management of ischaemic stroke and transient ischaemic attack 2010: a guideline from the South African Stroke Society (SASS) and the SASS Writing Committee. S Afr Med J 2010;100:747-778.

27. European Stroke Organisation (ESO) Executive Committee; ESO Writing Committee. Guidelines for management of ischaemic stroke and transient ischaemic attack 2008. Cerebrovasc Dis 2008;25:457-507.

28. National Institute for Health and Care Excellence (NICE). Meningitis (Bacterial) and Meningococcal Septicaemia in Under 16s: Recognition, Diagnosis and Management (CG102). London: NICE; 2010. Available at: nice.org. uk/guidance/cg102. Accessed April 24, 2016.

29. Boyles TH, Bamford C, Bateman K, et al. Guidelines for the management of acute meningitis in children and adults in South Africa. South Afr J Infect Dis 2013;28:5-15.

30. Glauser T, Shinnar S, Gloss D, et al. Evidence-based guideline: treatment of convulsive status epilepticus in children and adults: report of the guideline committee of the American epilepsy society. Epilepsy Curr 2016;16:48-61.

31. Meierkord H, Boon P, Engelsen B, et al. EFNS guideline on the management of status epilepticus in adults. Eur J Neurol 2010;17:348-355.

32. Nunes VD, Sawyer L, Neilson J, Sarri G, Cross JH. Diagnosis and management of the epilepsies in adults and children: summary of updated NICE guidance. BMJ 2012; 344:e281.

33. South African Medical Association-Neurological Association of South Africa Epilepsy Working Group. Epilepsy management at primary health care level.S Afr Med J 2000;90:401-432.

34. Mathers CD, Loncar D. Updated Projections of Global Mortality and Burden of Disease, 2002-2030: Data Sources, Methods and Results. Geneva: World Health Organization; 2005. Available at: who.int/healthinfo/statistics/ bod_projections2030_paper.pdf. Accessed April 24, 2016.

35. Yusuf S, Islam S, Chow CK, et al; Prospective Urban Rural Epidemiology (PURE) Study Investigators. Use of secondary prevention drugs for cardiovascular disease in the community in high-income, middle-income, and low-income countries (the PURE Study): a prospective epidemiological survey. Lancet 2011;378:1231-1243.

36. Berkowitz AL, Westover MB, Bianchi MT, Chou SH. Aspirin for acute stroke of unknown etiology in resource-limited settings: a decision analysis. Neurology 2014;83:787-793.

37. Nakibuuka J, Sajatovic M, Nankabirwa J, et al. Effect of a 72 hour stroke care bundle on early outcomes after acute stroke: a non randomised controlled study. PLoS One 2016;11:e154333. 


\section{Neurology}

\section{Standard operating procedures improve acute neurologic care in a sub-Saharan African setting}

Lamin E.S. Jaiteh, Stefan A. Helwig, Abubacarr Jagne, et al.

Neurology 2017;89;144-152 Published Online before print June 9, 2017

DOI 10.1212/WNL.0000000000004080

This information is current as of June 9, 2017

\author{
Updated Information \& \\ Services \\ Supplementary Material \\ References \\ Citations \\ Permissions \& Licensing \\ Reprints
}

including high resolution figures, can be found at:

http://n.neurology.org/content/89/2/144.full

Supplementary material can be found at:

http://n.neurology.org/content/suppl/2017/06/09/WNL.0000000000004 080.DC1

This article cites 32 articles, 9 of which you can access for free at: http://n.neurology.org/content/89/2/144.full\#ref-list-1

This article has been cited by 2 HighWire-hosted articles: http://n.neurology.org/content/89/2/144.full\#\#otherarticles

Information about reproducing this article in parts (figures,tables) or in its entirety can be found online at:

http://www.neurology.org/about/about_the_journal\#permissions

Information about ordering reprints can be found online:

http://n.neurology.org/subscribers/advertise

Neurology ${ }^{\circledR}$ is the official journal of the American Academy of Neurology. Published continuously since 1951, it is now a weekly with 48 issues per year. Copyright Copyright ( 2017 The Author(s). Published by Wolters Kluwer Health, Inc. on behalf of the American Academy of Neurology. All rights reserved. Print ISSN: 0028-3878. Online ISSN: 1526-632X.

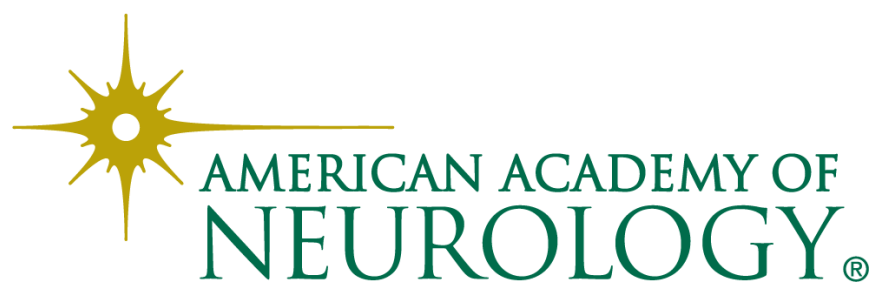

